\title{
Prone approach for minimally invasive esophagectomy: history and surgical approach
}

\author{
Alexander Leung, Alex R. Cedeño, Thomas Fabian \\ Division of Cardiothoracic Surgery, Albany Medical Center, Albany, NY, USA \\ Contributions: (I) Conception and design: All authors; (II) Administrative support: T Fabian; (III) Provision of study materials or patients: All authors; \\ (IV) Collection and assembly of data: All authors; (V) Data analysis and interpretation: All authors; (VI) Manuscript writing: All authors; (VII) Final \\ approval of manuscript: All authors. \\ Correspondence to: Alexander Leung, MD. Division of Cardiothoracic Surgery, Albany Medical Center, 43 New Scotland Avenue, MC-61 Albany, NY \\ 12208, USA. Email: leunga2@amc.edu.
}

\begin{abstract}
Esophagectomy has traditionally been a procedure wrought with significant morbidity. The advent of minimally invasive esophagectomy (MIE) has led to significant changes in outcomes. Starting originally as a hybrid open procedure, now most MIEs are done entirely via a laparoscopic and thoracoscopic approach with a neck approach if performing a cervical anastomosis. Using a completely minimally invasive approach has led to a decrease in postoperative morbidity as well as reduced wound and cardiopulmonary complications. Initially, the esophageal mobilization was performed via a left lateral decubitus approach. Later, the thoracic portion of the procedure was performed via a prone approach. The prone approach can aid in both visualization during surgery as well as decreased blood loss, improved lymph node harvest, decreased cardiopulmonary complications with no differences in morbidity and mortality.
\end{abstract}

Keywords: Esophageal cancer; minimally invasive esophagectomy (MIE); prone positioning; Ivor-Lewis esophagectomy

Received: 29 October 2019; Accepted: 17 January 2020; Published: 10 October 2020.

doi: $10.21037 /$ shc.2020.03.01

View this article at: http://dx.doi.org/10.21037/shc.2020.03.01

\section{Introduction}

Esophageal cancer remains one of the most difficult and frustrating cancers in terms of interventions as well as survival. It is 6th amongst cancers in mortality (1) with an overall 5 -year relative survival ranging from $15 \%$ to $25 \%(2,3)$. Generally asymptomatic until presenting with dysphagia and/or weight loss (4), much of the poor prognosis involving esophageal cancer is caused by the advanced stage of disease at time of diagnosis. The majority of patients have either metastatic or locally advanced disease at time of presentation with less than $25 \%$ of patients presenting with a localized stage for definitive treatment (5). Many treatment options exist for esophageal cancer ranging from chemotherapy and/or radiation followed by resection or even endoscopic options $(5,6)$. However, esophagectomy remains a mainstay for curative treatment in resectable disease.

Esophagectomy is considered one of the most challenging and complex surgical interventions with significant morbidity and mortality. Classically, esophagectomies have been performed through three different approaches: the transthoracic and transabdominal approach (Ivor-Lewis esophagectomy), the transthoracic, transabdominal, and transcervical approach (McKeown or three-field esophagectomy), and the transhiatal esophagectomy. Traditionally, mortality has ranged as wide as $3-25 \%$ with one paper reviewing SEER-Medicare database showing a $14 \%$ in-hospital mortality (7). The significant morbidity is the result of the risk of pulmonary complications, which reached as high as $57 \%$ (8), and notwithstanding the myriad of other cardiac, infectious 
and post-surgical complications (9).

\section{History of minimally invasive esophagectomy (MIE)}

Since the inception of minimally invasive surgery in the late 1980 's, there has been desire to improve the way we perform advanced surgical interventions applying these techniques. The evolution in foregut surgical techniques as well as technological improvements has significantly contributed to our ability to operate on the esophagus; it ultimately lead to the ability to remove and reconstruct the esophagus. Described in 1992 by Cuschieri (10), and further expanded on by Collard in 1993 (11), the concept of MIE has been a concept for over 2 decades. At that time, these minimally invasive approaches were performed as hybrid procedures (combined thoracoscopic and open) until Luketich et al. described totally MIE with good results and, until today, is the largest data available regarding this surgical intervention $(12,13)$.

As MIE evolved, multiple studies have compared this approach to traditional open surgery. Most agree that MIE has decreased the risks and complications from an open approach. From an operative standpoint, MIE has been shown to have decreased estimated blood loss, improved lymph node harvest, and decreased recurrent laryngeal nerve injury with no differences in R0 resection $(13,14)$. Multiple studies have also shown that MIE leads to decreased pulmonary infections, shorter ICU stays, shorter hospital stays, and better short-term quality of life $(12,15-17)$. Thirtyand 90-day mortality have also been found to be at least equivalent, if not better $(13,18)$. MIE was also noted to have improved patient-reported outcome measures and quality of life (17); 5-year mortality and disease-free survival however has not consistently been demonstrated to be different (19). The TIME trial, comparing MIE $v s$. open esophageal resection, showed no differences in 3-year overall survival rate and 3-year disease-free survival rates (17).

As the technology from MIE evolved and robotic surgery became implemented, the national trend has led to increased usage of both minimally invasive modalities. Approximately $47.6 \%$ of all esophagectomies were performed via a MIE or robotic-assisted approach (RAMIE), which is in contrast from $34.2 \%$ in 2010 (20). The MIE/RAMIE approach showed improved lymph node harvest compared to open esophagectomies with no differences in 30- and 90-day survival (20). The largest randomized controlled trial (ROBOT trial) compared RAMIE with open esophagectomy and showed decreased cardiopulmonary complications, decreased estimated blood loss with improved pain scores and short-term quality of life scores (21).

The benefits of MIE $v s$. open surgery seem simple for most. The lack of a thoracotomy and laparotomy eliminate the morbidity from the wounds and their potential complications, including preservation of potential cardiopulmonary compromise. However, multiple mechanisms have been proposed including overall technical improvements. Transition from McKeown to Ivor-Lewis technique has resulted in lower anastomotic rates and avoidance of violating the neck tissue plane $(22,23)$. Lastly, an additional benefit of MIE is in the prone positioning, which may show a benefit to lateral decubitus positioning $(16,23)$.

\section{Our surgical approach}

The surgical approach we employ at our institution is a MIE Ivor-Lewis approach for mid-esophageal and distalesophageal tumors in a modified semi-prone position. For patients with proximal tumors requiring a cervical anastomosis, we utilize the prone position followed by laparoscopy and neck anastomosis as described by Fabian et al. $(24,25)$. For the MIE Ivor-Lewis approach, the patient is placed in supine position to start and laparoscopy is performed to mobilize and create a gastric conduit and as well as placing a feeding jejunostomy. The patient is then placed in a semi-prone position for the thoracoscopic esophageal mobilization with removal of the specimen and esophagogastric anastomosis creation.

\section{The semi-prone position}

After intubation with a single-lumen endotracheal tube, the patient is placed in supine position. An esophagogastroduodenoscopy (EGD) is performed to confirm the tumor's location and extension and to evaluate the suitability of the stomach as an appropriate conduit. During the endoscopy, the pylorus is dilated with a balloon pneumatic device. After placement of the laparoscopic ports, the gastrohepatic attachments are mobilized and the esophagus is mobilized circumferentially around the hiatus. The stomach is mobilized with preservation of the right gastroepiploic vessels. The celiac lymph nodes are dissected, and the left gastric artery is transected with an endovascular GIA stapler. Short gastric vessels are transected using a harmonic device. The stomach is mobilized by dividing the gastrocolic omentum. The 


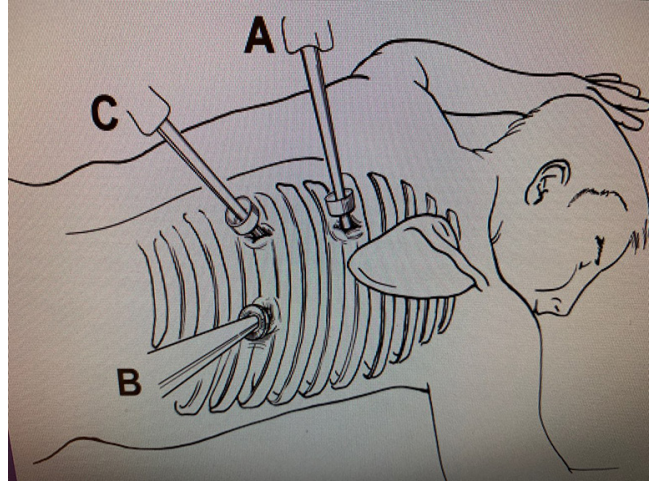

Figure 1 Illustrated schematic for thoracic port positions in prone positioning.

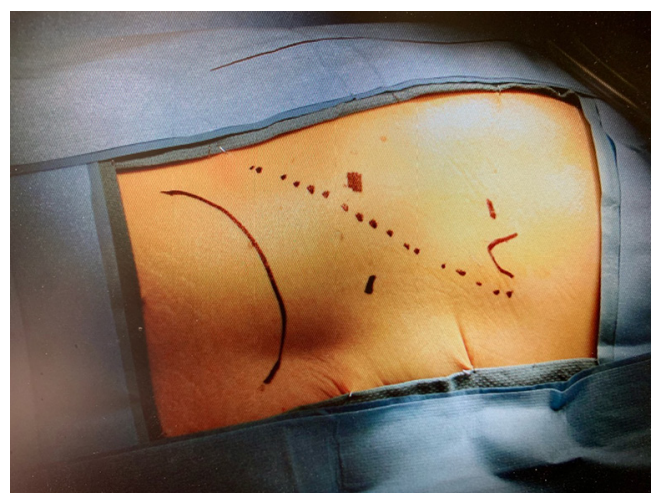

Figure 2 Preoperative marking of thoracic port placement during semi-prone position with anatomic markers.

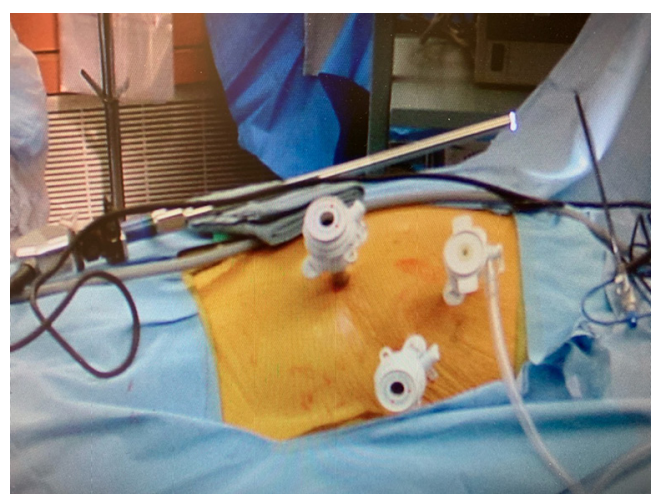

Figure 3 Thoracic port placement during semi-prone position using insufflation. An additional port placed posteriorly is sometimes used to aid in esophageal retraction. antrum is mobilized such that the pylorus can reach the right crus with no tension. Two hundred units of botulinum toxin $\left(\right.$ Botox $^{\mathrm{TM}}$ ) is injected in the pylorus in four quadrants for gastric emptying. The gastric conduit is formed with the endovascular GIA stapler. It is important to ensure the stapler is in a straight orientation to prevent twisting and potential spiraling of the conduit. A pedicled omental flap is created from the superior portion of the gastric conduit, which aids in preventing anastomotic leaks. The esophageal specimen is then attached to the gastric conduit. It is also important to ensure that when the specimens are attached to maintain appropriate orientation as the conduit can easily be twisted when the specimens are retrieved during the thoracoscopic portion of the procedure. Lastly, a feeding jejunostomy tube is placed prior to closure of the abdominal ports.

A double-lumen endotracheal tube is then placed, and the patient is then placed in a semi-prone position, which lies between the prone and left lateral decubitus positions (Figures 1,2). The angle between the patient's chest and the operating table is approximately $30-45$ degrees. Once our thoracoscopic ports are placed, we utilize insufflation (Figure 3), then we start by incising the mediastinal pleura to expose the anterior aspect of the esophagus. This dissection extends cephalad to the level of the azygous vein, which is then skeletonized and divided with an endovascular GIA stapler. The parietal pleura is then opened from the level of the azygous vein to the crura. Branches of the thoracic duct and the aorto-esophageal vessels are ligated with a harmonic device. The esophagus is then encircled with a penrose and used to provide countertraction to aid in the complete mobilization of the esophagus and to allow for an en bloc resection of the paraesophageal lymph nodes. After complete mobilization of the esophagus, the proximal esophagus is transected above the level of the azygous vein with an endovascular GIA stapler. A wound protector is placed in the extraction port to avoid contamination and the specimen is pulled up through the hiatus. While pulling the specimen from the abdomen, it is again important to apply continuous traction to prevent any twisting of the conduit as it enters the thoracic cavity. Once the specimen is removed, the conduit should be able to reach the proximal esophagus with no tension. A $25-\mathrm{mm}$ functional end-toend anastomosis (EEA) circular stapler is used to create 
an end-to-side anastomosis (26). An endovascular GIA stapler is then used to close the candy cane of the gastric conduit. The pedicled omental flap is then positioned over the anastomosis and a leak test is performed. A nasogastric tube is placed in the neoesophagus and a chest tube is placed adjacent to the anastomosis. Prior to extubation, a bronchoscopy is performed to clear all secretions from the airway.

\section{Prone approach}

Prone positioning has been described since 1994, when Cuschieri performed a thoracoscopic esophageal mobilization with the patient in prone position (27). Since then, while not as popular as the traditional lateral decubitus approach, this approach has its proponents as well as its benefits. The rationale behind a prone approach is that in the lateral decubitus position, the esophagus lies in the most dependent portion of the operative field. This position results in an obscure field of vision if there is any blood loss as it will also lay in this dependent position. Also, in the lateral decubitus position, there is a need for a skilled operative assistant to help aid in lung retraction. However, in the prone position, the esophagus lies superiorly in the operating field. The lung will also naturally retract anteriorly, and blood will generally pool away from the operative field $(24,28)$. The approach then potentially leads to shortened operative times and faster esophageal mobilization $(24,25)$. Outcomes from the prone position were first presented by Palanivelu in 2006, when he described low incidence of respiratory complications with low 30-day mortality rates (29). This data was then echoed in other studies comparing the prone approach with the lateral decubitus approach, showing a decrease in estimated blood loss, decrease in serious complications, decrease in pulmonary complications, and decrease in hospital stay with higher lymph node harvest (30-32). There were no differences in in-hospital morbidity and mortality $(31,33)$. These studies also showed no differences in disease-free survival and 5 -year survival rates $(30,32)$.

Prone positioning may have a benefit in the patient's ventilation during the operation. During a traditional lateral decubitus approach, ventilation is one-lung ventilation with lung isolation. The disadvantages with one-lung ventilation includes increased rate of respiratory complications and need for anesthesia induction/positioning for a double-lumen endotracheal tube $(34,35)$. With the lung not in the operative field, there is the ability for two-lung ventilation during the operation during this thoracic approach $(25,35,36)$. Two- lung ventilation can decrease the amount of atelectasis of the ventilated lung due to the pressure from the mediastinum in the lateral decubitus position as well as decreasing the amount of secretions in the dependent lung (37).

The concept of prone positioning has been wellestablished in the care of acute respiratory distress syndrome (ARDS) patients (38-40). As a result, prone positioning may be beneficial from improved respiratory and circulatory physiology (41). Comparisons of prone positioning $v s$. lateral decubitus positioning showed that patients had higher $\mathrm{PaO}_{2}$ to $\mathrm{FiO}_{2}$ ratios and lower $\mathrm{PaCO}_{2}$ levels in the perioperative period (42-45). Also, in the prone position, due to equal blood flow through both lungs, there is a reduction in the right-to-left pulmonary shunt, which can help alleviate the decreased $\mathrm{PaO}_{2}$ (45). As pulmonary complications are a high cause of morbidity during an esophagectomy, any potential benefits could lead to great improvements.

The additional benefit of a prone approach includes decreased surgeon fatigue due to a more ergonomic position $(25,36,41)$. One study showed that the operating in the prone position led to decreased mental demands and, subjectively, decreased musculoskeletal complaints (46). While it has been suggested that the prone approach may decrease operative time due to the improved visibility and dissection (25), further studies have shown that there was no statistically significant difference in operating time between the two approaches $(30,31,47)$.

As with normal MIE, RAMIE has been utilized using the prone approach. First described in 2006 (48), it has been associated with equivalent lymph node harvest and morbidity with the open approach (49). Like most new modalities, however, more studies will need to be published to evaluate long-term benefits.

However, the prone approach has some disadvantages. The most significant occurs if there is a need to convert to a thoracotomy $(25,36,41)$. While a rare situation, the additional time to reposition the patient can potentially result in increased morbidity. Another disadvantage is the generally unfamiliarity of this surgical orientation. The additional time necessary in placing a patient in prone position as well as the unfamiliar views obtained during this positioning may lead to increased operating times and/or initial learning curve. Lastly, airway management can be an issue if the prone procedure is performed under one-lung ventilation and with a standard endotracheal tube; if the procedure requires conversion to thoracotomy, then either a bronchial blocker would need to be placed or the original tube would have to be changed to 
a double-lumen endotracheal tube (36). As a result of these disadvantages, some have advocated the importance of patient selection in guiding which patients are preferable in a prone approach, including avoiding patients with severe pleural adhesions, bulky or locally infiltrative tumors, patients with prior definitive chemoradiation, patients with insufficient cardiopulmonary functions, and morbidly obese patients (37).

As a result, the semi-prone approach, which combines both elements of the prone and lateral decubitus approach, has become a favorable option. First described in 2011 (50), the semi-prone approach retains the benefits of prone positioning on improved esophageal exposure and lung retraction with the easier ability to convert to a posterolateral thoracotomy for an open approach (47). The semi-prone approach has been shown to have equivalent morbidity and mortality with similar lymph node harvest $(51,52)$. The RAMIE version of the semi-prone approach has also been described (53).

\section{Conclusions}

The prone and semi-prone approaches for MIE are both validated methods with improved operative visibility and better oxygenation without compromising overall survival.

\section{Acknowledgments}

Funding: None.

\section{Footnote}

Provenance and Peer Review: This article was commissioned by the Guest Editor (Ghulam Abbas) for the series "Minimally Invasive Esophageal Surgery" published in Shanghai Chest. The article has undergone external peer review.

Conflicts of Interest: All authors have completed the ICMJE uniform disclosure form (available at http://dx.doi. org/10.21037/shc.2020.03.01). The series "Minimally Invasive Esophageal Surgery" was commissioned by the editorial office without any funding or sponsorship. The authors have no other conflicts of interest to declare.

Ethical Statement: The authors are accountable for all aspects of the work in ensuring that questions related to the accuracy or integrity of any part of the work are appropriately investigated and resolved.
Open Access Statement: This is an Open Access article distributed in accordance with the Creative Commons Attribution-NonCommercial-NoDerivs 4.0 International License (CC BY-NC-ND 4.0), which permits the noncommercial replication and distribution of the article with the strict proviso that no changes or edits are made and the original work is properly cited (including links to both the formal publication through the relevant DOI and the license). See: https://creativecommons.org/licenses/by-nc-nd/4.0/.

\section{References}

1. Falk GW. Risk factors for esophageal cancer development. Surg Oncol Clin N Am 2009;18:469-85.

2. Gupta B, Kumar N. Worldwide incidence, mortality and time trends for cancer of the oesophagus. Eur J Cancer Prev 2017;26:107-18.

3. Hongo M, Nagasaki Y, Shoji T. Epidemiology of esophageal cancer: orient to Occident. Effects of chronology, geography and ethnicity. J Gastroenterol Hepatol 2009;24:729-35.

4. Enzinger PC, Mayer RJ. Esophageal cancer. N Engl J Med 2003;349:2241-52.

5. D'Journo XB, Thomas PA. Current management of esophageal cancer. J Thorac Dis 2014;6 Suppl 2:S253-64.

6. Shahbaz Sarwar CM, Luketich JD, Landreneau RJ, et al. Esophageal cancer: an update. Int J Surg 2010;8:417-22.

7. Ra J, Paulson EC, Kucharczuk J, et al. Postoperative mortality after esophagectomy for cancer: development of a preoperative risk prediction model. Ann Surg Oncol 2008; 15:1577-84.

8. Hulscher JB, van Sandick JW, de Boer AG, et al. Extended transthoracic resection compared with limited transhiatal resection for adenocarcinoma of the esophagus. $\mathrm{N}$ Engl J Med 2002;347:1662-9.

9. Griffin SM, Shaw IH, Dresner SM. Early complications after Ivor Lewis subtotal esophagectomy with two-field lymphadenectomy: risk factors and management. J Am Coll Surg 2002;194:285-97.

10. Cuschieri A, Shimi S, Banting S. Endoscopic oesophagectomy through a right thoracoscopic approach. J R Coll Surg Edinb 1992;37:7-11.

11. Collard JM, Lengele B, Otte JB, et al. En bloc and standard esophagectomies by thoracoscopy. Ann Thorac Surg 1993;56:675-9.

12. Luketich JD, Alvelo-Rivera M, Buenaventura PO, et al. Minimally invasive esophagectomy: outcomes in 222 patients. Ann Surg 2003;238:486-94; discussion 94-5. 
13. Luketich JD, Pennathur A, Awais O, et al. Outcomes after minimally invasive esophagectomy: review of over 1000 patients. Ann Surg 2012;256:95-103.

14. Fabian T, Martin JT, McKelvey AA, et al. Minimally invasive esophagectomy: a teaching hospital's first year experience. Dis Esophagus 2008;21:220-5.

15. Nguyen NT, Follette DM, Wolfe BM, et al. Comparison of minimally invasive esophagectomy with transthoracic and transhiatal esophagectomy. Arch Surg 2000;135:920-5.

16. Biere SS, van Berge Henegouwen MI, Maas KW, et al. Minimally invasive versus open oesophagectomy for patients with oesophageal cancer: a multicentre, open-label, randomised controlled trial. Lancet 2012;379:1887-92.

17. Straatman J, van der Wielen N, Cuesta MA, et al. Minimally invasive versus open esophageal resection: three-year follow-up of the previously reported randomized controlled trial: the TIME trial. Ann Surg 2017;266:232-6.

18. Luketich JD, Pennathur A, Franchetti Y, et al. Minimally invasive esophagectomy: results of a prospective phase II multicenter trial-the eastern cooperative oncology group (E2202) study. Ann Surg 2015;261:702-7.

19. Paireder M, Asari R, Kristo I, et al. Morbidity in open versus minimally invasive hybrid esophagectomy (MIOMIE): long-term results of a randomized controlled clinical study. Eur Surg 2018;50:249-55.

20. Espinoza-Mercado F, Imai TA, Borgella JD, et al. Does the approach matter? Comparing survival in robotic, minimally invasive, and open esophagectomies. Ann Thorac Surg 2019;107:378-85.

21. van der Sluis PC, van der Horst S, May AM, et al. Robot-assisted minimally invasive thoracolaparoscopic esophagectomy versus open transthoracic esophagectomy for resectable esophageal cancer: a randomized controlled trial. Ann Surg 2019;269:621-30.

22. Hoppo T, Jobe BA, Hunter JG. Minimally invasive esophagectomy: the evolution and technique of minimally invasive surgery for esophageal cancer. World J Surg 2011;35:1454-63.

23. Zhang J, Wang R, Liu S, et al. Refinement of minimally invasive esophagectomy techniques after 15 years of experience. J Gastrointest Surg 2012;16:1768-74.

24. Fabian T, Martin J, Katigbak M, et al. Thoracoscopic esophageal mobilization during minimally invasive esophagectomy: a head-to-head comparison of prone versus decubitus positions. Surg Endosc. 2008;22:2485-91.

25. Fabian T, McKelvey AA, Kent MS, et al. Prone thoracoscopic esophageal mobilization for minimally invasive esophagectomy. Surg Endosc 2007;21:1667-70.

26. Bizekis C, Kent MS, Luketich JD, et al. Initial experience with minimally invasive Ivor Lewis esophagectomy. Ann Thorac Surg 2006;82:402-6; discussion 406-7.

27. Cuschieri A. Thoracoscopic subtotal oesophagectomy. Endosc Surg Allied Technol 1994;2:21-5.

28. Goldberg RF, Bowers SP, Parker M, et al. Technical and perioperative outcomes of minimally invasive esophagectomy in the prone position. Surg Endosc 2013;27:553-7.

29. Palanivelu C, Prakash A, Senthilkumar R, et al. Minimally invasive esophagectomy: thoracoscopic mobilization of the esophagus and mediastinal lymphadenectomy in prone position--experience of 130 patients. J Am Coll Surg 2006;203:7-16.

30. Kuwabara S, Kobayashi K, Kubota A, et al. Comparison of perioperative and oncological outcome of thoracoscopic esophagectomy in left decubitus position and in prone position for esophageal cancer. Langenbecks Arch Surg 2018;403:607-14.

31. Markar SR, Wiggins T, Antonowicz S, et al. Minimally invasive esophagectomy: Lateral decubitus vs. prone positioning; systematic review and pooled analysis. Surg Oncol 2015;24:212-9.

32. Miura S, Nakamura T, Miura Y, et al. Long-term outcomes of thoracoscopic esophagectomy in the prone versus lateral position: a propensity score-matched analysis. Ann Surg Oncol 2019;26:3736-44.

33. Bonavina L, Scolari F, Aiolfi A, et al. Early outcome of thoracoscopic and hybrid esophagectomy: propensitymatched comparative analysis. Surgery 2016;159:1073-81.

34. Shen $\mathrm{Y}$, Zhong M, Wu W, et al. The impact of tidal volume on pulmonary complications following minimally invasive esophagectomy: a randomized and controlled study. J Thorac Cardiovasc Surg 2013;146:1267-73; discussion 1273-4.

35. Cai L, Li Y, Sun L, et al. Better perioperative outcomes in thoracoscopic-esophagectomy with two-lung ventilation in semi-prone position. J Thorac Dis 2017;9:117-22.

36. Jarral OA, Purkayastha S, Athanasiou T, et al. Thoracoscopic esophagectomy in the prone position. Surg Endosc 2012;26:2095-103.

37. Koyanagi K, Ozawa S, Tachimori Y. Minimally invasive esophagectomy performed with the patient in a prone position: a systematic review. Surg Today 2016;46:275-84.

38. Guérin C, Reignier J, Richard JC, et al. Prone positioning in severe acute respiratory distress syndrome. N Engl J 
Med 2013;368:2159-68.

39. Scholten EL, Beitler JR, Prisk GK, et al. Treatment of ARDS with prone positioning. Chest 2017;151:215-24.

40. Kallet RH. A comprehensive review of prone position in ARDS. Respir Care 2015;60:1660-87.

41. Noshiro H, Miyake S. Thoracoscopic esophagectomy using prone positioning. Ann Thorac Cardiovasc Surg 2013;19:399-408.

42. Tanaka E, Okabe H, Kinjo Y, et al. Advantages of the prone position for minimally invasive esophagectomy in comparison to the left decubitus position: better oxygenation after minimally invasive esophagectomy. Surg Today 2015;45:819-25.

43. Otsubo D, Nakamura T, Yamamoto M, et al. Prone position in thoracoscopic esophagectomy improves postoperative oxygenation and reduces pulmonary complications. Surg Endosc 2017;31:1136-41.

44. Yatabe T, Kitagawa H, Yamashita K, et al. Better postoperative oxygenation in thoracoscopic esophagectomy in prone positioning. J Anesth 2010;24:803-6.

45. Bonavina L, Laface L, Abate E, et al. Comparison of ventilation and cardiovascular parameters between prone thoracoscopic and Ivor Lewis esophagectomy. Updates Surg 2012;64:81-5.

46. Shen Y, Feng M, Tan L, et al. Thoracoscopic esophagectomy in prone versus decubitus position: ergonomic evaluation from a randomized and controlled study. Ann Thorac Surg 2014;98:1072-8.

\section{doi: 10.21037/shc.2020.03.01}

Cite this article as: Leung A, Cedeño AR, Fabian T. Prone approach for minimally invasive esophagectomy: history and surgical approach. Shanghai Chest 2020;4:44.
47. Lin J, Kang M, Chen C, et al. Thoracoscopic oesophageal mobilization during thoracolaparoscopy three-stage oesophagectomy: a comparison of lateral decubitus versus semiprone positions. Interact Cardiovasc Thorac Surg 2013;17:829-34.

48. Dapri G, Himpens J, Cadiere GB. Robot-assisted thoracoscopic esophagectomy with the patient in the prone position. J Laparoendosc Adv Surg Tech A 2006;16:278-85.

49. Kim DJ, Hyung WJ, Lee CY, et al. Thoracoscopic esophagectomy for esophageal cancer: feasibility and safety of robotic assistance in the prone position. J Thorac Cardiovasc Surg 2010;139:53-9.e1.

50. Gao Y, Wang Y, Chen L, et al. Comparison of open threefield and minimally-invasive esophagectomy for esophageal cancer. Interact Cardiovasc Thorac Surg 2011;12:366-9.

51. Li X, Lai FC, Qiu ML, et al. Minimally invasive esophagectomy in the lateral-prone position: experience of 226 cases. Surg Laparosc Endosc Percutan Tech 2016;26:60-5.

52. Seesing MFJ, Goense L, Ruurda JP, et al. Minimally invasive esophagectomy: a propensity score-matched analysis of semiprone versus prone position. Surg Endosc 2018;32:2758-65.

53. Ishikawa N, Kawaguchi M, Inaki N, et al. Robotassisted thoracoscopic hybrid esophagectomy in the semi-prone position under pneumothorax. Artif Organs 2013;37:576-80. 